This is an electronic reprint of the original article. This reprint may differ from the original in pagination and typographic detail.

Author(s): Murphy, Luke J.; Robertson, Katherine N.; Harroun, Scott G.; Brosseau, Christa L.; Werner-Zwanziger, Ulrike; Moilanen, Jani; Tuononen, Heikki; Clyburne, Jason A. C.

Title: A Simple Complex on the Verge of Breakdown: Isolation of the Elusive Cyanoformate Ion

Year: $\quad 2014$

Version:

Please cite the original version:

Murphy, L. J., Robertson, K. N., Harroun, S. G., Brosseau, C. L., Werner-Zwanziger, U., Moilanen, J., Tuononen, H., \& Clyburne, J. A. C. (2014). A Simple Complex on the Verge of Breakdown: Isolation of the Elusive Cyanoformate Ion. Science, 344(6179), 75-78. https://doi.org/10.1126/science.1250808

All material supplied via JYX is protected by copyright and other intellectual property rights, and duplication or sale of all or part of any of the repository collections is not permitted, except that material may be duplicated by you for your research use or educational purposes in electronic or print form. You must obtain permission for any other use. Electronic or print copies may not be offered, whether for sale or otherwise to anyone who is not an authorised user. 


\title{
Title: A Simple Complex on the Verge of Breakdown: Isolation of the Elusive Cyanoformate Ion
}

Authors: Luke J. Murphy, ${ }^{1}$ Katherine N. Robertson, ${ }^{1}$ Scott G. Harroun, ${ }^{1}$ Christa L. Brosseau, ${ }^{1}$ Ulrike Werner-Zwanziger, ${ }^{2}$ Jani Moilanen, ${ }^{3}$ Heikki M. Tuononen, ${ }^{3 *}$ Jason A.C. Clyburne ${ }^{1 *}$

\begin{abstract}
Affiliations:
${ }^{1}$ The Atlantic Centre for Green Chemistry, Department of Chemistry, Saint Mary's University, Halifax, Nova Scotia, B3H 3C3, Canada. Tel: 019024205827.

2 Department of Chemistry and Institute for Research in Materials, Dalhousie University, Halifax, Nova Scotia, B3H 4J3, Canada.

${ }^{3}$ Department of Chemistry, P.O. Box 35, FI-40014, University of Jyväskylä, Finland. Tel: 358 452358588.
\end{abstract}

*Correspondence to: jason.clyburne@smu.ca; heikki.m.tuononen@jyu.fi

\begin{abstract}
:
Why does cyanide not react destructively with the proximal iron centre at the active site of 1-aminocyclopropane-1-carboxylic acid (ACC) oxidase, an enzyme central to the biosynthesis of ethylene in plants? It has long been postulated that the cyanoformate anion, $\left[\mathrm{NCCO}_{2}\right]^{-}$, forms and then decomposes to $\mathrm{CO}_{2}$ and $\mathrm{CN}^{-}$during this process. We have now isolated and crystallographically characterized this elusive anion as its tetraphenylphosphonium salt. Theoretical calculations show that cyanoformate has a very weak $\mathrm{C}-\mathrm{C}$ bond and that is thermodynamically stable only in low dielectric media. Solution stability studies have substantiated the latter result. We propose that cyanoformate shuttles the potentially toxic cyanide away from the low dielectric active site of ACC oxidase, before breaking down in the higher dielectric medium of the cell.
\end{abstract}

\section{Main Text:}

Nature manifests a myriad of efficient strategies to manage and manipulate reactive small molecules, such as water, hydrogen peroxide, carbon dioxide and oxygen, in the sensitive environs of enzyme active sites. The cyanoformate ion, $\left[\mathrm{NCCO}_{2}\right]^{-}$, a complex of carbon dioxide and cyanide, has been implicated in the biosynthesis of ethylene $(1,2)$ but because it has eluded detection in condensed media the details of its decomposition have not been elucidated. Ethylene is an important plant hormone that regulates such essential biological processes as fruit ripening $(3,4)$. Its production is catalyzed by the enzymes 1-aminocyclopropane-1-carboxylic acid (ACC) synthase, which generates ACC, and ACC oxidase, which converts ACC to ethylene, cyanide and carbon dioxide. A simplified mechanism of the reaction catalysed by ACC oxidase is provided in Fig. 1. Mechanistic and structural studies strongly support binding of ACC and oxygen to the iron centre located in the active site of ACC oxidase. Sequential single-electron transfer from the co-factor, ascorbate, with elimination of water generates an iron(IV)-oxo species, followed by ring-opening of bound ACC to eliminate ethylene and cyanoformate, which then decomposes to $\mathrm{CN}^{-}$and $\mathrm{CO}_{2}$. It is not definitively known whether this decomposition occurs 
at the active site or elsewhere (5). Bicarbonate has been identified as an essential mediator for proton transfer in the process (6-8).
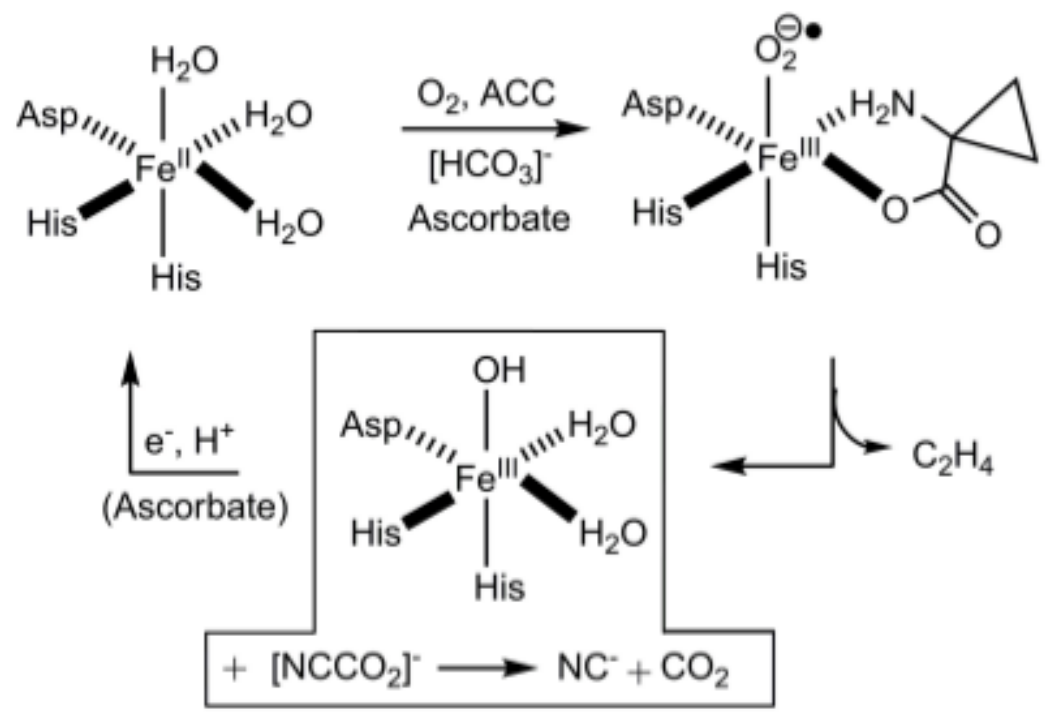

Figure 1: Simplified reaction scheme for the generation of ethylene, cyanide and carbon dioxide from ACC, via cyanoformate, at the active site of ACC oxidase.

It remains unclear as to how the iron-containing active site of ACC oxidase is protected from the cyanide by-product, a known deactivating agent of iron-containing enzymes in general and $\mathrm{Fe}(\mathrm{III})$ in particular (9). Although the hydrogen cyanide is ultimately metabolised, primarily by $\beta$-cyanoalanine synthase to produce the amino acid $\beta$-cyanoalanine (10), coordination to the iron center of ACC oxidase would seem likely beforehand. A recent publication by Dilley et al. (11) revealed that ACC oxidase is activated at cyanide concentrations between 0.1 to $1 \mathrm{mM}$ whereas above $1 \mathrm{mM}$ the cyanide becomes inhibitory. These authors propose that cyanide is bound as a ligand to Fe(II) in ACC oxidase, which then assists ACC binding. It should be noted, vis-à-vis our later discussion, that in most studies cyanide levels are typically determined from the bulk plant material $(12,13)$ rather than intra- or extra-cellularly. How then are the higher levels of cyanide removed from the active site of ACC oxidase for safe metabolisation? We believe that the generation of cyanoformate, a simple coordination complex of cyanide and $\mathrm{CO}_{2}$, plays a vital role in this regard.

Surprisingly, much of the fundamental coordination chemistry of $\mathrm{CO}_{2}$, particularly with regards to small ligands and their corresponding reactivity, has yet to be explored. For example, little is known of the reactions between carbon dioxide and halides or pseudo-halides (i.e., $\mathrm{OH}$, $\left.\mathrm{CN}, \mathrm{OCN}, \mathrm{SCN}, \mathrm{N}_{3}, \ldots\right)$, although this gap can be attributed, at least partially, to the instability of these donor-acceptor complexes. There are only two well-characterised families of halide/pseudo-halide complexes of $\mathrm{CO}_{2}$, the more common being bicarbonates, species that form numerous materials stabilized through extensive hydrogen bonding (14). The only other known example is fluorocarbonate, $\left[\mathrm{FCO}_{2}\right]^{-}$. This deceptively simple anion, isoelectronic with $\left[\mathrm{NO}_{3}\right]^{-}$, 
might superficially be predicted to be stable, but it has only recently been prepared, and the fluoride affinity of carbon dioxide was calculated to be $-111 \mathrm{~kJ} \mathrm{~mol}^{-1}$, which "appears to be the lower limit for a reaction" (15).

We began our investigation into the possibility of isolating cyanoformate with a preliminary computational study. Table S6 of the supplementary material includes a full list of the calculated energies for the association reaction of $\mathrm{CO}_{2}$ and $\mathrm{CN}^{-}$. At all of the levels of theory employed the formation of cyanoformate was found to be thermodynamically favoured in vacuo. However, the binding energy of $\mathrm{CO}_{2}$ was even smaller than that of the aforementioned fluorocarbonate ion. With the computations indicating that a thermodynamically stable, albeit very fragile, species could exist, we set out to try and isolate a derivative. We had recently shown that higher order zincates could be stabilized and isolated from ion rich media using tetraphenylphosphonium halide salts (16). Using a similar approach, we exposed a concentrated solution of $\left[\mathrm{PPh}_{4}\right] \mathrm{CN}$ to an atmosphere of $\mathrm{CO}_{2}$, and colorless crystals immediately precipitated. The solvent was decanted and the crystals were isolated and characterized using crystallographic and spectroscopic techniques. Solid state NMR of both singly-labelled $\left[\mathrm{PPh}_{4}\right]\left[\mathrm{NC}^{13} \mathrm{CO}_{2}\right]$ and doubly-labelled $\left[\mathrm{PPh}_{4}\right]\left[\mathrm{N}^{13} \mathrm{C}^{13} \mathrm{CO}_{2}\right]$ isotopologues confirmed formation of the complex with $\delta\left(\underline{C O}_{2}\right)=144.4 \mathrm{ppm}$, consistent with the chemical shift observed for the fluorocarbonate ion, $c a$. $142 \mathrm{ppm}$ (15). The bonding between the cyano and carbonyl groups was also confirmed by direct observation of one bond coupling $\left({ }^{1} \mathrm{~J}_{13 \mathrm{C}-13 \mathrm{C}}=61( \pm 4) \mathrm{Hz}\right)$ between the ${ }^{13} \mathrm{C}$-labelled carboxyl and ${ }^{13} \mathrm{C}$-labelled cyano fragments, based on the resolved ${ }^{13} \mathrm{CO}_{2}$ signal in the spectrum of the latter compound (see Fig. S19).
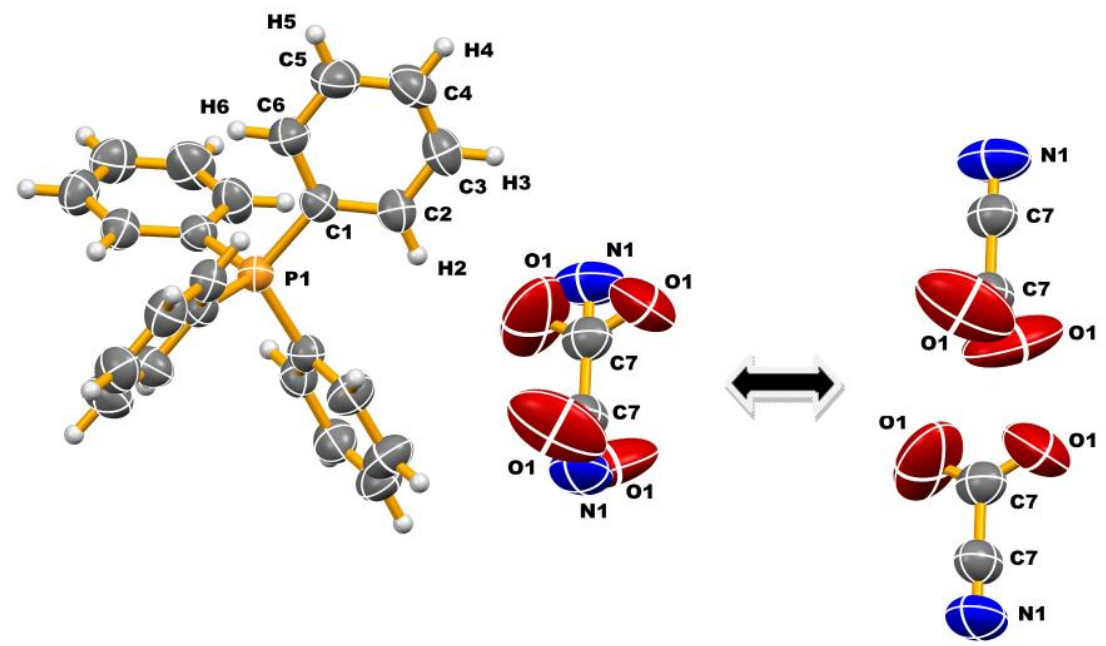

Figure 2: Solid state structure of [ $\left.\mathrm{PPh}_{4}\right]\left[\mathrm{NCCO}_{2}\right]$. Thermal ellipsoids are drawn at the $50 \%$ probability level. Unique atoms of the cation and all atoms of the anion are labelled. The anion comprises only three unique atoms, carbon and oxygen atoms with site occupancies of 0.50 and nitrogen with a site occupancy of 0.25 . The remainder of the anion is generated by symmetry. To the right of the arrow the anion has been deconvoluted into its two overlapping components, both of which have $50 \%$ occupancy in the crystal structure. 
Figure 2 shows the structure of $\left[\mathrm{PPh}_{4}\right]\left[\mathrm{NCCO}_{2}\right]$ as determined by single crystal $\mathrm{x}$-ray diffraction (see Figs. S32 and S33, Tables S11-S17 and the accompanying supplementary discussion for further details). Isolation of the fragile anion in the solid state was likely aided by the crystal lattice stabilization of the salt. The $\mathrm{C}-\mathrm{C}$ bond in the anion (1.480(9) $\AA$ ) is equal to that reported by Drück et al. (17) in the structure of cyanoformamide, $\mathrm{NCC}(\mathrm{O}) \mathrm{NH}_{2}$. The cyanide $\mathrm{C}-\mathrm{N}$ bond length $(1.056(12) \AA)$ proved to be significantly shorter than that in cyanoformamide (1.141(8) $\AA$ ). Investigation of bond lengths reported in the Cambridge Structural Database (CSD) (18) showed that the observed cyanide bond length is reasonable, if relatively short, suggesting the presence of a strong $\mathrm{CN}$ bond with only a weak $\mathrm{C}-\mathrm{C}$ interaction to the $\mathrm{CO}_{2}$ portion of the adduct. The strengthening of the $\mathrm{CN}$ interaction in the cyanide ligand upon coordination to electron deficient sites has previously been discussed in the literature (19).

The packing of the ions in the structure of $\left[\mathrm{PPh}_{4}\right]\left[\mathrm{NCCO}_{2}\right]$ in the tetragonal space group $I-4$, is similar to that observed in many other simple [ $\left.\mathrm{PPh}_{4}\right] \mathrm{X}$ salts, where $\mathrm{X}=\mathrm{Br}, \mathrm{I}, \mathrm{SCN}, \mathrm{OCN}$, $\mathrm{N}(\mathrm{CN})_{2}$, etc. (20-24). Viewed down the $Z$ axis, the cations and anions form discrete stacked columns. Because of the large size of the cations, the anions can be thought of as occupying the channels formed between the stacked columns of cations. There are few inter-ion interactions in the structure and those that are present are generally long and presumably weak. Only the interaction $\mathrm{C}(2)-\mathrm{H}(2) \ldots \mathrm{O}(1)^{\prime}$ is characterised by a separation of less than $2.5 \AA, \mathrm{H}(2) \ldots \mathrm{O}(1)^{\prime}=$ $2.37 \AA$. The lack of strong interactions between the ions likely results in the relatively free rotation of the anion about the $S_{4}$ rotation axis in the cavity produced by the parallel stacking of the cations down the $Z$ axis.

The theoretically predicted metrical parameters of $\left[\mathrm{NCCO}_{2}\right]^{-}$show very little variation with respect to the employed method and are in good overall agreement with the results from the $\mathrm{X}$-ray structural study, although some small systematic deviations do exist; numeric data are presented in Table S4. Heterolytic splitting of the $\mathrm{C}-\mathrm{C}$ bond in the anion and subsequent analysis of the bonding energy contributions (electrostatic, orbital interactions and Pauli repulsion) using the Ziegler-Rauk-Morokuma energy decomposition procedure (25-27) show that the linear cyanide and bent carbon dioxide fragments interact predominately $(c a .90 \%)$ via a $\sigma$-type donoracceptor interaction (28). Furthermore, the results show that the fragile nature of the adduct arises not so much because of the intrinsic characteristics of the $\mathrm{C}-\mathrm{C}$ bond but because of the significant energy release ( $\mathrm{ca} .200 \mathrm{~kJ} \mathrm{~mol}^{-1}$ ) associated with linearization of the $\mathrm{CO}_{2}$ fragment (29). The morphologies of the key frontier orbitals as well as the results from the analysis of the electron localisation function of cyanoformate are both consistent with the view of cyanide acting as a two electron donor to carbon dioxide (see Figs. S29 and S30 and the accompanying supplementary discussion for full details). Hence, the $\mathrm{C}-\mathrm{C}$ interaction in $\left[\mathrm{NCCO}_{2}\right]^{-}$is similar to the bonding in adducts of $\mathrm{CO}_{2}$ with $\mathrm{N}$-heterocyclic carbenes (30-33), though, to our knowledge, the latter systems have not been subjected to a thorough theoretical treatment.

Ionic carboxylates exhibit two characteristic C-O stretching bands in their IR spectra. The higher energy asymmetric band $\left(v_{\mathrm{as}} \mathrm{CO}_{2}\right)$ typically appears as a very strong and broad band, whereas the lower energy band $\left(v_{\mathrm{s}} \mathrm{CO}_{2}\right)$ is usually less intense. The spectra collected on samples of $\left[\mathrm{PPh}_{4}\right]\left[\mathrm{NCCO}_{2}\right]$, Figs. S3-S5, exhibit both of these expected signals. Consistent with the theoretical predictions for the IR and Raman bands (Tables S8-S10), the cyano stretch (vCN) is not observed in the infrared spectrum, but is clearly visible in the Raman (2196 $\mathrm{cm}^{-1}$, Fig. S7). This frequency, when compared to that of other cyano groups, such as in acetonitrile $\left(2253 \mathrm{~cm}^{-1}\right.$, 
Fig. S6) and $\left[\mathrm{PPh}_{4}\right] \mathrm{CN}\left(2069 \mathrm{~cm}^{-1}\right.$, Fig. S10), supports the notion of a strong $\mathrm{CN}$ interaction in $\left[\mathrm{NCCO}_{2}\right]^{-}$. We also prepared ${ }^{13} \mathrm{C}$-labelled samples to confirm our assignments and this data is included in the supplementary material.

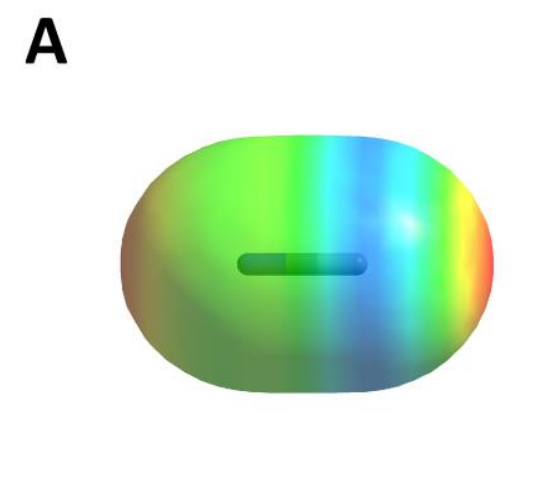

$-0.285$

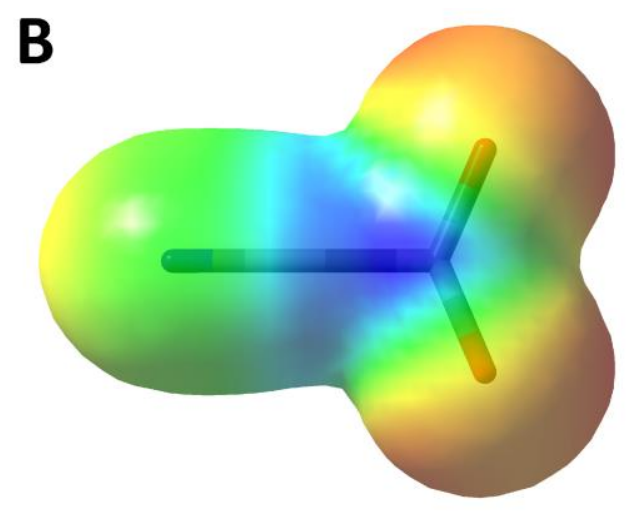

$-0.250$

$-0.100$

Figure 3: Electrostatic potentials (atomic units) superimposed on the total electron density isosurface (0.01 a.u.) of (A) $\mathrm{CN}^{-}$and $(\mathrm{B})$ [ $\left.\mathrm{NCCO}_{2}\right]^{-}$at the $\omega \mathrm{B97X-D/aug-cc-pVTZ}$ level of theory.

To visualize the effect of cyanide coordinating to $\mathrm{CO}_{2}$, we have superimposed maps of the electrostatic potential on the total electron density of the reactant and product ions (Fig. 3). These plots aid in the assessment of reactivity, in particular prediction of potential sites of attack for nucleophiles and electrophiles. In $\mathrm{CN}^{-}$, the surface around the carbon atom is electron poor compared to the nitrogen center, but both atoms have electron rich areas directly on the bond axis, consistent with the two possible coordination modes for this anion. The electrostatic potential of $\left[\mathrm{NCCO}_{2}\right]^{-}$shows that it is now the oxygen centers that are electron rich and therefore the most favored sites for electrophilic interactions. This suggests that hydrogen bond donors and acidic metals will be attracted more favourably to the oxygen atoms, rather than to the cyanide portion of the $\left[\mathrm{NCCO}_{2}\right]^{-}$anion. The delicate interplay of nucleophilic and electrophilic interactions is very important in supporting the many biological reactions involving $\mathrm{CO}_{2}$ (34) and the chemistry of the cyanoformate anion is no exception in this regard.

We have also calculated the thermodynamics for the formation of cyanoformate as a function of various solvents at different density functional levels of theory (see Figs. 4 and S31, Table S7 and the accompanying supplementary discussion for full details). The results suggest that $\left[\mathrm{NCCO}_{2}\right]^{-}$is thermodynamically stable only in non-polar solvents (toluene); in high dielectric media the anion becomes thermodynamically unstable with respect to fragmentation to $\mathrm{CN}^{-}$and $\mathrm{CO}_{2}$ (Fig. 4). However, the anion is kinetically stabilized, albeit not by much, in all media as breaking the $\mathrm{C}-\mathrm{C}$ bond has an activation barrier of approximately $40 \mathrm{~kJ} \mathrm{~mol}^{-1}$ at these levels of theory. Although many enzymatic processes occur in bulk water, the local dielectric constant at the active site of an enzyme is typically low $(7,35)$, in the range of 4-20, as compared to 78 for water $(36,37)$. In the cell, at the low dielectric active site of the ACC oxidase enzyme, the cyanide ions could remain complexed with $\mathrm{CO}_{2}$ in the form of $\left[\mathrm{NCCO}_{2}\right]^{-}$, protecting the iron 
centre from attack. However, as the cyanoformate anion migrates out to the bulk aqueous solution of the cytoplasm, the thermodynamics are modified, and the complex decomposes to the observed products, namely hydrogen cyanide and carbon dioxide.

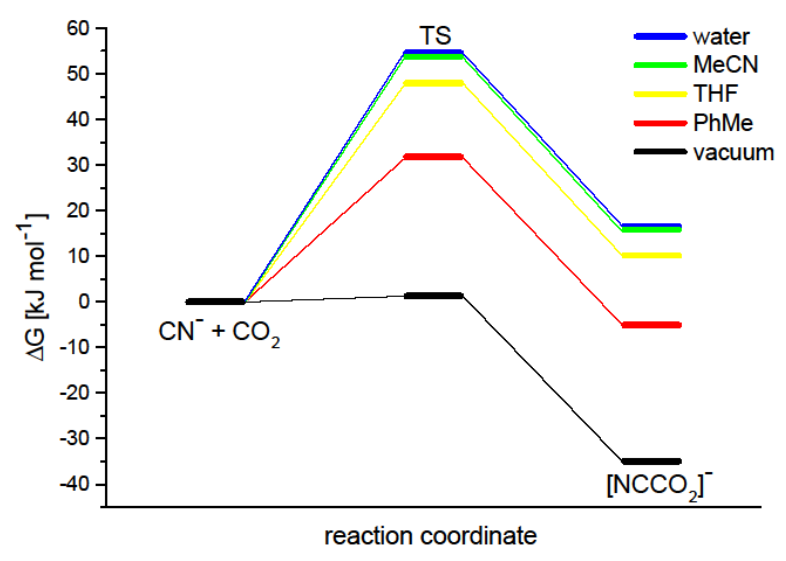

Figure 4: Calculated reaction profile for the formation of $\left[\mathrm{NCCO}_{2}\right]^{-}$from $\mathrm{CN}^{-}$and $\mathrm{CO}_{2}$ at the $\omega B$ 97X-D/aug-cc-pVTZ level with different solvent models.

The pivotal role assigned to the cyanoformate anion, based on its calculated (in)stability in solutions of different dielectric constant, was bolstered by carrying out further decomposition experiments (see the supplementary discussion for full details). Because of the insolubility of $\left[\mathrm{PPh}_{4}\right]\left[\mathrm{NCCO}_{2}\right]$ in many traditional solvents, these studies were performed on tetrabutylammonium cyanoformate, $\left[\mathrm{Bu}_{4} \mathrm{~N}\right]\left[\mathrm{NCCO}_{2}\right]$, generated in situ from the cyanide precursor, in the ionic liquid (IL) trihexyl(tetradecyl)phosphonium bis(trifluoromethylsulfonyl)imide, $\left[\mathrm{P}_{66614}\right][\mathrm{TFSI}]$. An aliquot of the $\left[\mathrm{Bu}_{4} \mathrm{~N}\right]\left[\mathrm{NCCO}_{2}\right] / \mathrm{IL}$ solution was added to the scrupulously dried solvent being studied and the disappearance of the $v_{\text {as }} \mathrm{CO}_{2}$ peak of cyanoformate $\left(1689 \mathrm{~cm}^{-1}\right)$ monitored using real time Fourier transform (FT) IR spectroscopy. Half-lives were determined from linear regressions of plots of $\ln \left(\mathrm{P} / \mathrm{P}_{0}\right)$, the ratio of peak height $(\mathrm{P})$ to initial peak height $\left(\mathrm{P}_{0}\right)$, versus time $(\mathrm{t})$. Solution half-lives for cyanoformate of 110 minutes, 55 minutes and 17 minutes were calculated for toluene, tetrahydrofuran and acetonitrile, respectively. As predicted by theory, the stability of the cyanoformate anion in solution rapidly decreased with increasing dielectric constant of the solution.

Although large scale experimental studies of the hydrolysis of cyanoformate were not feasible because of the possible release of $\mathrm{HCN}$, the theoretical behaviour of the cyanoformate anion in aqueous environments was investigated in more detail by performing geometry optimizations ( $\omega$ B97X-D/aug-cc-pVTZ level) that included explicit $\mathrm{H}_{2} \mathrm{O}$ molecules in addition to the bulk solvent (see the supplementary discussion for full details). In all cases, the calculations minimized to hydrogen bonded structures $(\mathrm{O} \cdots \mathrm{H}$ and/or $\mathrm{N} \cdots \mathrm{H})$ with no indication of spontaneous hydrolysis. Although a concerted hydrolysis of cyanoformate in water thus seems unlikely, a sequential pathway can be envisioned. As shown computationally, cyanoformate readily 
dissociates into $\mathrm{CN}^{-}$and $\mathrm{CO}_{2}$ in high dielectric media and the cyanide anion is an excellent nucleophile that can easily abstract a proton from water ( $\mathrm{pKa}$ of $\mathrm{HCN}=9.24$ ). The hydroxide ions generated can, in turn, attack the electrophilic carbon of $\mathrm{CO}_{2}$ to yield the bicarbonate anion. Thus, in an aqueous environment containing dissolved $\mathrm{CO}_{2}$, the addition of cyanide will lead to the formation of bicarbonate. This is a possible explanation for the observed activation of ACC oxidase by cyanide (11), since bicarbonate is an important participant in the catalytic cycle of the enzyme (6-8).

Our experimental work has clearly shown that cyanoformate is readily converted to bicarbonate (and $\mathrm{HCN}$ ) in the presence of even a trace of water. Early attempts to isolate the cyanoformate salt often gave crystals of tetraphenylphosphonium bicarbonate, whose structure has been confirmed by crystallographic analysis. In our ${ }^{13} \mathrm{C} \mathrm{NMR}$ study, the presence of a peak at $162.3 \mathrm{ppm}$ is certainly attributable to bicarbonate, as the chemical shift correlates well with that reported for other such salts (38). That the bicarbonate originates from the added $\mathrm{CO}_{2}$ is supported by the large size of this peak relative to others in the same spectrum, as ${ }^{13} \mathrm{CO}_{2}$ was used in the original synthesis. We also probed the decomposition of the synthesized cyanoformate salts in a protic solvent by monitoring the $v_{\mathrm{as}} \mathrm{CO}_{2}$ stretch of the cyanoformate anion $\left(1689 \mathrm{~cm}^{-1}\right)$ with real time FTIR as 1-propanol was added to a dilute $\left[\mathrm{Bu}_{4} \mathrm{~N}\right]\left[\mathrm{O}_{2} \mathrm{CCN}\right] / \mathrm{IL}$ solution. This peak rapidly diminished during the addition while concomitantly a peak corresponding to bicarbonate appeared at $1652 \mathrm{~cm}^{-1}(39)$. Over the course of only two minutes, $v_{\mathrm{as}} \mathrm{CO}_{2}$ for cyanoformate disappeared completely, while the bicarbonate peak reached a steady absorbance. All of the observed experimental results are entirely consistent with the computationally based proposal of a stepwise process for the decomposition and hydrolysis of the cyanoformate anion.

The stability of cyanoformate, a simple anion of $\mathrm{CO}_{2}$ coordinated to $\mathrm{CN}^{-}$, has been shown to be dependent on the dielectric constant of its local environment. We propose that this property allows it to shuttle toxic $\mathrm{CN}^{-}$away from the low dielectric active site of the enzyme ACC oxidase before its decomposition in higher dielectric media. In broader terms, the ability to manipulate solution stability of otherwise unstable or transient species, through changes to the dielectric constant, should find other important applications.

\section{Acknowledgments:}

We thank the Natural Sciences and Engineering Research Council of Canada (through the Discovery Grants Program to JACC) and the Academy of Finland (through its Research Fellowship to HMT). JACC acknowledges generous support from the Canada Research Chairs Program, the Canadian Foundation for Innovation and the Nova Scotia Research and Innovation Trust Fund. HMT acknowledges generous support from the Academy of Finland, the Technology Industries of Finland Centennial Foundation and the University of Jyväskylä. This work was also supported in part by GreenCentre Canada, Encana Corporation (Deep Panuke Education \& Training and Research \& Development Fund), Springboard and the Magnus Ehrnrooth Foundation (postdoctoral scholarship to JM). We are grateful to NMR-3 (Dalhousie University) for NMR data acquisition, Canadian Microanalytical Services for elemental analyses and the Finnish Grid Infrastructure consortium for CPU time. We also thank Dr. E. Plettner for her helpful discussions and Dr. T.S. Cameron and Dr. A. Linden for their crystallographic insights. Metrical parameters for the structure of tetraphenylphosphonium cyanoformate are 
available free of charge from the Cambridge Crystallographic Data Centre, under reference number CCDC 986380.

\section{References}

${ }^{1}$ D. Adams, S. F. Yang, Ethylene the gaseous plant hormone: mechanism and regulation of biosynthesis. Trends. Biochem. Sci 6, 161 (1981).

2 G. D. Peiser, et al., Formation of cyanide from carbon 1 of 1-aminocycloprpane-1-carboxylic acid during its conversion to ethylene. Proc. Nat. Acad. Sci. 81, 3059 (1984).

${ }^{3}$ H. Qiao, et al., Processing and subcellular trafficking of ER-tethered EIN2 control response to ethylene gas. Science 338, 390 (2012).

${ }^{4}$ S. P. Burg, E. A. Burg, Ethylene action and the ripening of fruits. Science 148, 1190 (1965).

${ }^{5}$ N. M.W. Brunhuber, et al., Steady-state kinetic mechanism of recombinant avocado ACC oxidase: initial velocity and inhibitor studies. Biochem. 39, 10730 (2000).

${ }^{6}$ M. C. Pirrung, Ethylene biosynthesis from 1-aminocyclopropanecarboxylic acid. Acc. Chem. Res. 32, 711 (1999).

${ }^{7}$ A. Bassan, T. Borowski, C. J. Schofield, P. E. M. Siegbahn, Ethylene biosynthesis by 1-aminocyclopropane-1carboxylic acid oxidase: A DFT study. Chem. Eur. J. 12, 8835 (2006).

${ }^{8} \mathrm{~L}$. M. Mirica, J. P. Klinman, The nature of $\mathrm{O}_{2}$ activation by the ethylene-forming enzyme 1-

aminocyclopropane-1-carboxylic acid oxidase. Proc. Nat. Acad. Sci. 105, 1814 (2008).

${ }^{9} \mathrm{~S}$. Shima, et al., The crystal structure of [Fe]-hydrogenase reveals the geometry of the active site. Science 321, 572 (2008).

10 J. M. Miller, E. E. Conn, Metabolism of hydrogen cyanide by higher plants. Plant. Physiol. 65, 1199 (1980).

11 D. R. Dilley, et al., ACCO reaction mechanism and putative post-translational activities of the ACCO protein. AoB Plants Advance Access published August 1, 2013, doi: 10.1093/aobpla/plt031.

12 W. -K. Yip, S. F. Yang, Cyanide metabolism in relation to ethylene production in plant tissues. Plant. Physiol. 88, 473 (1988).

13 J. M. Smith, R. N. Arteca, Molecular control of ethylene production by cyanide in Arabidopsis thaliana. Physiol. Plant. 109, 180 (2000).

${ }^{14} \mathrm{D}$. Braga, et al., $\mathrm{O}-\mathrm{H} \cdots \mathrm{O}$ interactions involving doubly charged anions: charge compression in carbonatebicarbonate crystals. Chem. Eur. J. 8, 1173 (2002).

${ }^{15} \mathrm{X}$. Zhang, U. Gross, K. Seppelt, Fluorocarbonate, [ $\left.\mathrm{FCO}_{2}\right]$ :: preparation and structure. Angew. Chem., Int. Ed., Engl. 34, 1858 (1995).

16 I. S. MacIntosh, et al., Isolation and structures of two new organozinc anions from solutions rich in halide ions. Organometallics, 29, 2063 (2010).

17 U. Drück, W. Becker, G. Becker, Molecular and crystal structure of cyanoformamide. Z. Kristallogr. 167, 131 (1984).

${ }^{18}$ F. H. Allen, The CSD System: The Cambridge Structural Database: a quarter of a million crystal structures and rising. Acta Crystallogr., Sect. B: Struct. Sci. 58, 380 (2002).

${ }^{19} \mathrm{~K}$. F. Purcell, $\sigma$ and $\pi$ binding effects in the coordination of carbon monoxide and comparison with cyanide ion. J. Am. Chem. Soc. 91, 3487 (1969).

${ }^{20}$ N. W. Alcock, M. Pennington, G. R. Willey, Structure of tetraphenylphosphonium bromide. Acta Crystallogr., Sect. C: Cryst. Struct. Commun. 41, 1549 (1985).

${ }^{21}$ E. E. Schweizer, C. J. Baldacchini, A. L. Rheingold, Tetraphenylphosphonium chloride monohydrate, tetraphenylphosphonium bromide and tetraphenylphosphonium iodide. Acta Crystallogr., Sect. C: Cryst. Struct. Commun. 45, 1236 (1989).

${ }_{22}$ M. Köckerling, J. B. Willems, Crystal structure of tetraphenylphosphonium thiocyanate, $\left(\mathrm{C}_{6} \mathrm{H}_{5}\right)_{4} \mathrm{P}(\mathrm{SCN}) . Z$. Kristallogr.- New. Cryst. Struct. 214, 460 (1999).

${ }^{23}$ A. Bernsdorf, M. Köckerling, Crystal structure of tetraphenylphosphonium cyanate, $\left[\mathrm{P}\left(\mathrm{C}_{6} \mathrm{H}_{5}\right)_{4}\right] \mathrm{OCN} . \mathrm{Z}$. Kristallogr.- New. Cryst. Struct. 227, 85 (2012).

24 I. Ling, Y. Alias, A. N. Sobolev, C. L. Raston, Hirshfeld surface analysis of phosphonium salts. CrystEngComm, 12, 4321 (2010).

${ }^{25} \mathrm{~K}$. Morokuma, Molecular orbital studies of hydrogen bonds. III. C-O $\cdots \mathrm{H}-\mathrm{O}$ hydrogen bond in $\mathrm{H}_{2} \mathrm{CO} \cdots \mathrm{H}_{2} \mathrm{O}$ and $\mathrm{H}_{2} \mathrm{CO} \cdots 2 \mathrm{H}_{2} \mathrm{O}$. J. Chem. Phys. 55, 1236 (1971). 
${ }^{26}$ K. Kitaura, K. Morokuma, A new energy decomposition scheme for molecular interactions within the Hartree-Fock approximation. Int. J. Quantum Chem. 10, 325 (1976).

${ }^{27}$ T. Ziegler, A. Rauk, On the calculation of bonding energies by the Hartree Fock Slater method. I. The Transition State Method. Theoret. Chim. Acta 46, 1 (1977).

${ }^{28}$ D. Himmel, I. Krossing, A. Schnepf, Dative bonds in main-group compounds: a case for fewer arrows. Angew. Chem. Int. Ed. 53, 370 (2014).

${ }^{29}$ I. V. Alabugin, B. Gold, M. Shatruk, K. Kovnir, Comment on "Single-crystal x-ray structure of 1,3-

dimethylcyclobutadiene by confinement in a crystalline matrix". Science 330, 1047 (2010).

${ }^{30} \mathrm{H}$. Zhou, W. -Z. Zhang, C. -H. Liu, J. -P. Qu, X. -B. Lu, $\mathrm{CO}_{2}$ adducts of $N$-heterocyclic carbenes: thermal stability and catalytic activity toward the coupling of $\mathrm{CO}_{2}$ with epoxides. J. Org. Chem. 73, 8039 (2008).

${ }^{31}$ H. A. Duong, T. N. Tekavec, A. M. Arif, J. Louie, Reversible carboxylation of N-heterocyclic carbenes. Chem. Commun. 112 (2004).

$32 \mathrm{~J}$. D. Holbrey, et al., 1,3-Dimethylimidazolium-2-carboxylate: the unexpected synthesis of an ionic liquid precursor and carbene- $\mathrm{CO}_{2}$ adduct. Chem. Commun. 28 (2003).

${ }^{33}$ N. Kuhn, M. Steimann, G. Weyers, Synthesis and properties of 1,3-diisopropyl-4,5-dimethylimidazolium-2carboxylate. A stable carbene adduct of carbon dioxide. Z. Naturforsch., Teil B 54, 427 (1999).

${ }^{34}$ A. M. Appel et al., Frontiers, opportunities, and challenges in biochemical and chemical catalysis of $\mathrm{CO}_{2}$ fixation. Chem. Rev. 113, 6621 (2013).

35 M. Shoukry, S.S. Hassan, Thermodynamic investigation of the binary and ternary complexes involving 1aminocyclopropane carboxylic acid with reference to plant hormone. Cent. Eur. J. Chem. 12, 318 (2014).

${ }^{36} \mathrm{~J}$. J. Dwyer, et al., High apparent dielectric constants in the interior of a protein reflect water penetration. Biophys. J. 79, 1610 (2000).

${ }^{37}$ B. E. García-Moreno, et al., Experimental measurement of the effective dielectric in the hydrophobic core of a protein. Biophys. Chem. 64, 211 (1997).

${ }^{38} \mathrm{~F}$. Mani, M. Peruzzini, P. Stoppioni, $\mathrm{CO}_{2}$ absorption by aqueous $\mathrm{NH}_{3}$ solutions: speciation of ammonium carbamates, bicarbonate and carbonate by a ${ }^{13} \mathrm{C}$ NMR study. Green Chem. 8, 995 (2006).

${ }^{39}$ F. A. Miller, C. H. Wilkins, Infrared spectra and characteristic frequencies of inorganic ions. Anal. Chem. 24, 8, 1253 (1952). 